\title{
Media Usage Survey: How Engineering Instructors and Students Use Media
}

\author{
Gerd Gidion ${ }^{1}$, Luiz Fernando Capretz ${ }^{2}$, \\ Michael Grosch ${ }^{1}$, Ken N. Meadows ${ }^{2}$ \\ ${ }^{1}$ Karlsruhe Institute of Technology \\ ${ }^{2}$ University of Western University \\ \{gidion, michael.grosch\}@kit.edu \\ \{lcapretz, kmeadow2\}@uwo.ca
}

\begin{abstract}
Web 2.0 has ubiquitously penetrated academia. The dissemination of online information services in higher education has led to substantial changes in faculty teaching methods as well as the learning and study behavior of students. For example, the use of online services, such as Google and Wikipedia, has become mandatory not only during teaching and learning activities but also during leisure time for students and faculty. At the same time, traditional information media such as textbooks and printed handouts still form the basic pillars of teaching and learning. This article explains the preliminary results of a survey about media usage in teaching and learning conducted with Western University faculty and students, highlighting trends for the usage of new and traditional media in higher education. Furthermore, the article intends to participate in the ongoing discussion of practices and policies that purport to advance the effective use of media in teaching and learning.
\end{abstract}

Keywords: Media Usage Habits, Teaching and Learning Technology, Educational Survey

\section{INTRODUCTION}

The integration of IT media and services in higher education has led to substantial changes in the ways in which both students and instructors study, learn, and teach (Dahlstrom, 2012; Johnson, 2012). Accordingly, a survey of students' and instructors' media usage habits has been conducted at Western University in 2013. This survey purports to measure the extent to which media services are used in teaching and learning as well as to assess changes in media usage patterns. In addition, the survey comprises part of an international research program in which 20 universities from 10 countries are currently participating. For Western, the survey signifies a landmark, as it is the first of its kind in Canada and represents the initial foray into the North American postsecondary sector. Future plans involve conducting a comparative global media survey in the area of higher education.

The survey focuses primarily on the media usage habits of students and instructors. Based on an assessment of the way in which media use relates to teaching and learning, the identification of trends aims to provide an evidence base upon which more reliable predictions can anticipate future trends of media usage in higher education.

In this study, media is defined as technology that supports and extends human communication. Information represents a unidirectional form of communication and, therefore, information services are also understood as media services. In the field of digital media, where the content lacks attachment to a physical data carrier, media services include software as well as hardware services. Because software media can be transferred to different hardware, the latter is necessary for software access, and thus, hardware constitutes an integral component of the definition.

Media acceptance, which entails the second focus of this research, provides an indicator of media use quality from the participants' perspective. Therefore, media quality is assessed by measuring the acceptance of the services used by students and instructors.

\section{RESEARCH METHODOLOGY}

The Media Usage Survey was developed to provide researchers with a deeper and more detailed understanding of students' and instructors' technology usage in learning and of possible environmental factors that may influence that usage. This survey intends to incorporate the entire spectrum of media services, focusing on the following objectives: 
- evaluating media use in detail, including media use frequency, satisfaction with and acceptance of both internal or university-provided and external services, print media, electronic text, social media, information technology, communication media, e-learning services, and IT hardware;

- determining factors that might influence media use in learning, such as cultural differences, age, sex, and academic level as well as identifying similarities among student media usage;

- creating a knowledge base for universities to understand the media usage of students and instructors as well as establishing a longitudinal international survey on technology use in tertiary education;

- assessing prospective media trends and supporting the definition of media development as one of the strategic concepts at universities.

\subsection{The Survey}

The survey uses a fully standardized anonymous questionnaire containing a total of 150 items. Specifically, the tool measures usage frequency and user satisfaction with 53 media services, including

- information services such as Google search, Google Books, library catalogues, printed books, e-books, printed journals, e-journals, Wikipedia, open educational resources, and bibliographic software;

- communication services such as internal and external email, Twitter, and Facebook;

- e-learning services such as learning platforms and wikis;

- media hardware such as Wi-Fi, notebooks, tablet computers, desktop computers, and smartphones.

These variables, as well as the aforementioned methodology, were used to create an acceptance value. Additional variables also underwent evaluation, such as learning behavior, media usage in leisure time, educational biography, and socio-demographic factors.

The survey tool was first developed in 2009 and used at Karlsruhe Institute of Technology (KIT) (Grosch\&Gidion, 2011; Grosch 2012). During the course of 15 follow-up surveys that were administered on an international basis, the original survey underwent optimization, translation into several languages, and validation. In this study, the survey was administered at Western University with undergraduate students and faculty members in January and February of 2013. The instructor survey, which resembles the student questionnaire, intends to compare the media usage of students and instructors by examining possible divergences in media culture that may create problems in the use of media for studying and teaching.

\subsection{Survey Procedure}

The data for this survey was collected online using an established survey provider such as Unipark. During the collection and analysis process, Western researchers have been granted priority access to the data. Western researchers, in cooperation with research team members at the KIT, conducted the standardized and comparative analysis. Initial invitations to participate in the research and two reminders were sent by email. Both faculty and student surveys were both voluntary and anonymous, as indicated in the distributed letters. For the student survey, three e-mails were sent by Office of the Registrar staff to a stratified random sample of undergraduate and graduate students enrolled on main campus in the Winter 2013 academic term. The faculty survey involved a similar procedure and targeted faculty teaching on main campus during the Winter 2013 academic term.

\subsection{Response Rate}

In the period between January 16th and February 15th 2013, 19, 978 students were invited to respond to the survey. Subsequently, exactly 1584 visits occurred at the survey website. Among the invited students, 1266 started to answer the questions, 985 completed the survey, and 803 recorded a completion rate of more than $90 \%$.

\begin{tabular}{|c|c|c|c|c|c|}
\hline & & \multicolumn{2}{|c|}{ Students } & \multicolumn{2}{|c|}{ Instructors } \\
\hline & & $\begin{array}{c}\text { Fre- } \\
\text { quency }\end{array}$ & $\begin{array}{c}\text { Valid } \\
\%\end{array}$ & $\begin{array}{c}\text { Fre- } \\
\text { quency }\end{array}$ & $\begin{array}{l}\text { Valid } \\
\%\end{array}$ \\
\hline \multirow{8}{*}{$\begin{array}{l}\text { Va- } \\
\text { lid }\end{array}$} & Science & 173 & 21.9 & 23 & 12.3 \\
\hline & Engineering & 56 & 7.1 & 11 & 5.9 \\
\hline & Health Sciences & 125 & 15.8 & 21 & 11.2 \\
\hline & Social Science & 237 & 30.0 & 38 & 20.3 \\
\hline & $\begin{array}{l}\text { Arts and } \\
\text { Humanities }\end{array}$ & 82 & 10.4 & 15 & 8.0 \\
\hline & Other & 116 & 14.7 & 79 & 42.2 \\
\hline & Total & 789 & 100 & 187 & 100 \\
\hline & Missing & 196 & & 23 & \\
\hline $\begin{array}{l}\text { To- } \\
\text { tal }\end{array}$ & & 985 & & 210 & \\
\hline
\end{tabular}

Table 1 shows the response numbers for students and instructors that answered the question regarding the faculty of their primary area of study or primary teaching assignment.

In the period between January 29th and February 28th, approximately 1, 400 instructors were solicited by email to answer the survey. During this time, exactly 332 visits occurred at the survey website. While 252 faculty 
members started to answer the questions, 210 of them completed the survey.

While participants were randomly selected from a broad spectrum of demographic characteristics and faculties, female students were more heavily represented in terms of respondents. Otherwise, with some caveats, respondents are generally regarded as representative of the January and February 2013 student and instructor population at Western.

Further analysis of the survey requires interpretation about additional information concerning the current habits of media use for studying and teaching. In addition, the survey presents several limitations, including the reality that survey results fail to explain facts or observable behavior; rather, the answers merely analyze participants' response to given questions.

\section{FINDINGS}

\subsection{Media Usage in Free Time}

The students have been asked about their use of diverse media in their free time. The results show a general intensive use of Facebook and video sharing websites (e.g., Youtube). Reading books and watching TV, two traditional media habits, were only used moderately. Certain media use like playing computer games are, for most students, less relevant VVery new media such as Google+ seem not to be relevant, at least at the time of the survey. It To determine if there were differences between students from different faculties, we compared students from the five 5 most largest faculties (see Figure 1).

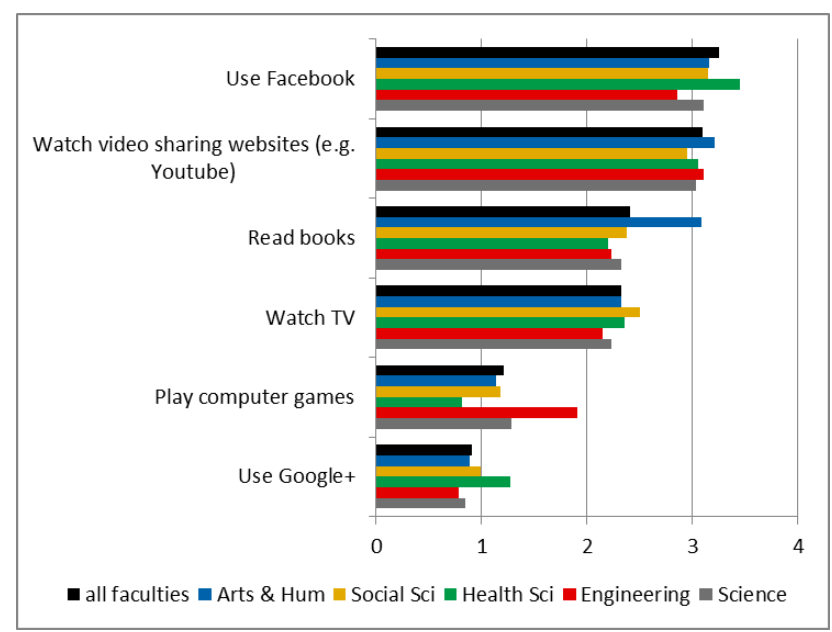

Fig. 1: The survey asked Western students from different faculties how often they performed various online activities during their free time (valid $\mathrm{n}=973-980$ ). The rating scale offered items such as "never" (0), "rarely" (1), "sometimes" (2), "often" (3), and "very often" (4).
We did find significant differences $(\mathrm{p}<.01)$ between the faculties on the items "Read books", with Arts and Humanities reporting reading more books than all other students, and the item "Play computer games", with reporting engineering students reporting a higher frequency of playing games than health science students.

\subsection{Students Usage Frequency of Media}

The findings concerning media use during free time provide some foundation for interpreting students' media use for teaching and learning, the primary focus of this research.

Google search is the most commonly used web service by all students for learning and study purposes, with as a moderately close second. Facebook is only in moderate use for learning and Twitter and Google+ are quite infrequently used for this purpose.

Significant differences in the use of Wikipedia were evident, with the students from health sciences reported more frequent use for learning than students from science engineering (see Figure 2).

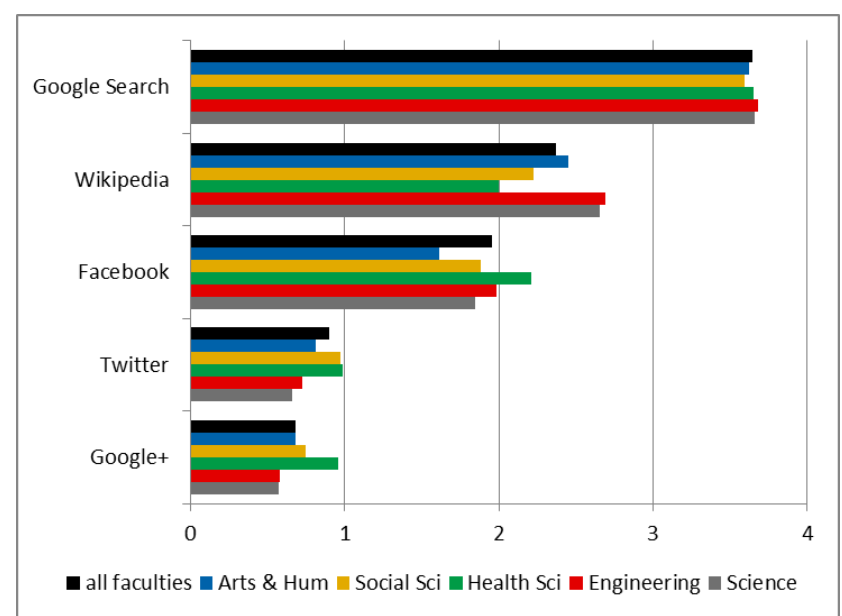

Fig. 2: The next question asked Western students how often they use various media for learning/studying (valid $n=957-979$ ). The question was rated on a five-point Likert scale with the following choices: "never" (0), "rarely" (1), "sometimes" (2), "often" (3), and "very often" (4).

The use of both printed and electronic documents for learning purposes was also assessed. The documents provided by the instructor are reported to be the three most frequently used types of documents (i.e., lecture notes, slides, and handouts). Printed books are less frequently used than the course documents but are more frequently used than Google books. On the other hand electronic academic periodicals are more often used than print-versions of these documents. Online materials from other universities are less frequently used than the all of the other media versions. 
Significant faculty differences were found for the items "online slides (from instructors" with students from science and health science reporting a higher frequency of usage students from arts \& humanities and social science (see Figure 3).

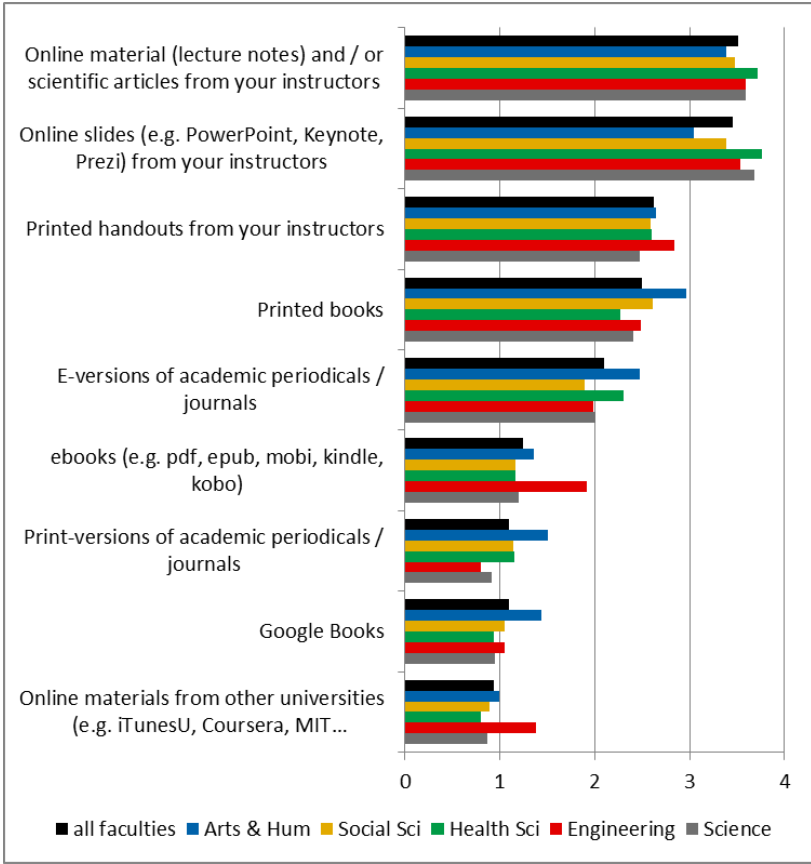

Fig. 3: Western students were queried about how often they used a selection of materials for learning/studying (valid $n=957-$ 979). The question was rated according to the following scale: "never" (0), "rarely" (1), "sometimes" (2), “often" (3), and "very often" (4).

In regarding to frequency of use of e-learning media, learning management systems are most used. This is not surprising as they are often a required component of students' courses. The use of video sharing websites such as Youtube is only moderately used for learning purposes. The frequency of use of recorded lectures, audio and video), and online self-tests for studying are both used rarely to moderately with course-based e-learning applications and course-based wikis being rarely used and mobile apps for learning such as iTunesU and iBooks) and game-based learning applications rarely to never used for learning.

Significant faculty differences are apparent for the item "online (self) tests for studying", with Arts and Humanities students being less frequent than students from all of the three other compared faculties. Also, there were significant differences on the use of recorded lectures, with Science students reporting more frequent usage than the other students (See Figure 4).

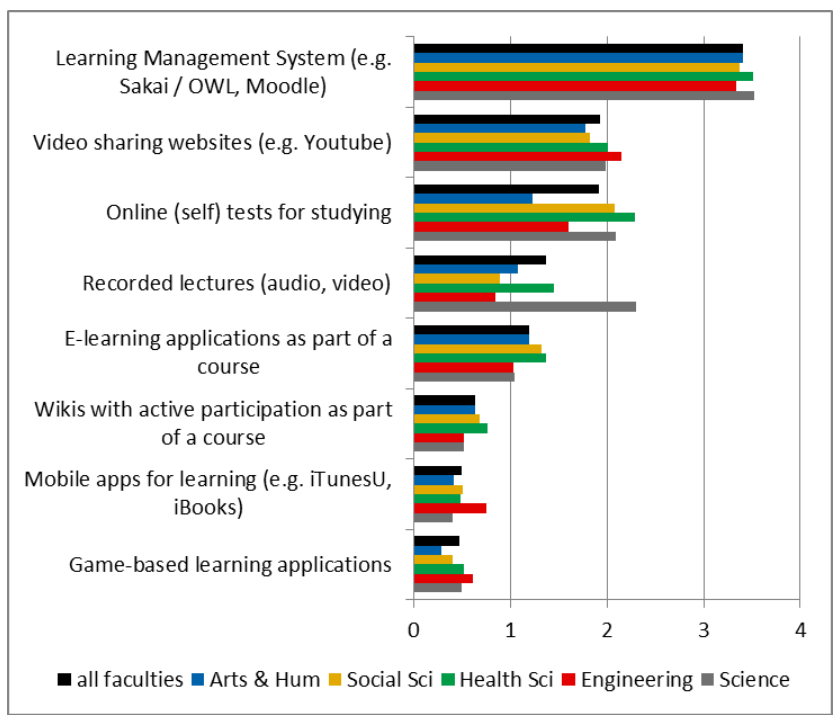

Fig. 4: The final question asked to Western students involves the frequency with which they use certain items for learning/studying (valid $\mathrm{n}=957-979$ ). The scale upon which these items are rated is as follows: "never" (0), "rarely" (1), "sometimes" (2), "often" (3), and "very often" (4).

\subsection{Students and Instructors}

Since the student questionnaire was essentially similar to that for instructors, excluding a few minor changes in wording, the instructors' results can be interpreted similar to those of the students.

Within the group of items constituting e-learning media, the instructors frequently use the learning management system; specifically, $62.1 \%$ of instructors use such items "(very) often," while $18.3 \%$ of faculty members "never" use this system. For this item, the mean of all instructors was 2.63 , and the SD was 1.59 . As is the case with students, the instructors also rated learning management systems as the most frequently used media. The second most-frequently used application entails video sharing websites; $25.5 \%$ of instructors use this item "(very) often," while only $34.6 \%$ state that they "never" use video sharing websites. In this media, the mean of all instructors is 1.49 , while the $\mathrm{SD}$ is 1.41 . Several items incur moderate usage; for instance, the e-learning application is used "(very) often" by $20.1 \%$ of instructors, while $40.2 \%$ of faculty members "never" use this technology. The mean of all instructors is 1.27 and the SD is 1.34. Furthermore, $12.5 \%$ of professors use recorded lectures "(very) often," while $52.4 \%$ of instructors "never" implement this technology; the mean of all instructors is .94 , while the $\mathrm{SD}$ is 1.2. For online (self) tests for students, $11.2 \%$ of instructors use this application "(very) often," but $66 \%$ of professors "never" utilize this media. The mean of all instructors is .67, with a SD of 1.14. In this case, the differences among the faculties demonstrate different variation than that of the students. The least relevant technologies seem to include Wikis, mobile 
learning apps, and game-based learning applications. $7.2 \%$ of instructors use Wikis "(very) often", while an overwhelming $73.2 \%$ of professors "never" use Wikis; the mean of all instructors is .49, with a SD of .98. Moreover, mobile apps for learning are used "(very) often" by only $8.2 \%$ of professors, while $60.1 \%$ of instructors "never" utilize this technology. In this case, the mean of all instructors corresponds to .45 , while the $\mathrm{SD}$ is .95 . Finally, a mere $3.4 \%$ of instructors use game-based learning applications "(very) often," while $82 \%$ teachers state that they "never" use this media. The mean of all instructors is .3 and the SD is .75.

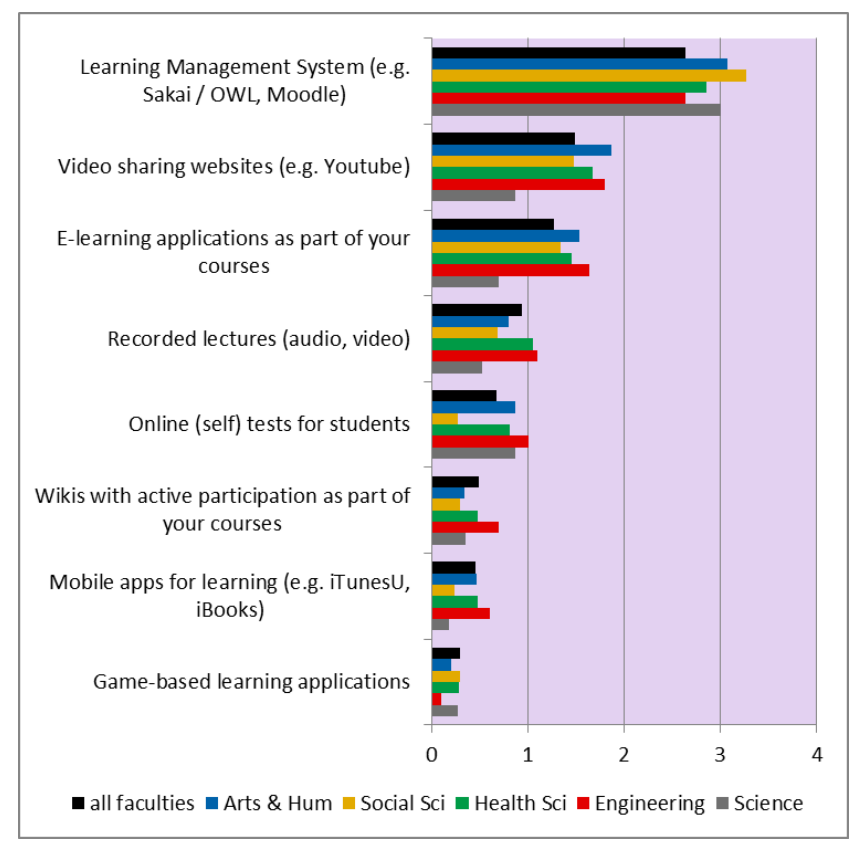

Fig. 5: The above chart shows Western instructors' response to the question: How often do you use the following for your academic work (i.e. teaching, research, service)? The validity is $\mathrm{n}=203-209$; the responses are rated on the following scale: "never" (0), "rarely" (1), "sometimes" (2), "often" (3), and "very often" (4).

\section{CONCLUSION}

The results of this study support the assumption that media usage of students and instructors include a mixture of traditional and new media. The main traditional media continue to be important, and some new media have emerged as seemingly on equal footing or even more important than the traditional forms of media. Some new media that have been in the public spotlight recently, do not seem to be as important as expected. These new media may still be emerging but it is not possible to know that at this point. There was some variation in media usage across faculties but perhaps not as much variation as might have been expected. Of particular interest to the primary investigator, an Engineer, was that students from Engineering were only significantly different than their fellow students in their frequency of usage of a small number of media(e.g., computer games). instructors show some differences in their reported media usage, but there were notable similarities as well, such as the seemingly pervasive use of Google search.

\section{References}

Dahlstrom, Eden: ECAR Study of Undergraduate Students and Information Technology, Educause Center for Applied Research, Louisville, CO 2012, http://net.educause.edu/ir/library/pdf/ERS1208/ERS1208. pdf. Last accessed January, 13, 2012.

Grosch, M. \& Gidion, G. (2011). Mediennutzungsgewohnheiten im Wandel (German). Ergebnisse einer Befragung zur studiumsbezogenen Mediennutzung (German). Karlsruhe: KIT Scientific Publishing. $\quad$ http://digbib.ubka.unikarlsruhe.de/volltexte/1000022524. Last accessed January, 13, 2012.

Grosch, M. (2012). Mediennutzung im Studium. Eine empirische Untersuchung am Karlsruher Institut für Technologie (German). Aachen: Shaker.

Johnson, L., Smith, R., Willis, H., Levine, A., \& Haywood, K., (2011). The 2011 Horizon Report. Austin, Texas: The New Media Consortium. http://www.nmc.org/pdf/2005_Horizon_Report.pdf. Last accessed January, 13, 2012. 